TITLE:

\title{
Avian seed dispersal in a mycoheterotrophic orchid Cyrtosia septentrionalis
}

\section{$\operatorname{AUTHOR}(\mathrm{S})$ :}

Suetsugu, Kenji; Kawakita, Atsushi; Kato, Makoto

\section{CITATION:}

Suetsugu, Kenji ...[et al]. Avian seed dispersal in a mycoheterotrophic orchid Cyrtosia septentrionalis. Nature Plants 2015, 1: 15052.

\section{ISSUE DATE:}

2015-05-05

URL:

http://hdl.handle.net/2433/197830

\section{RIGHT:}

(C) 2015 Macmillan Publishers Limited.; 許諾条件により本文は2015-1105 に公開.; This is not the published version. Please cite only the published version.; この論文は出版社版でありません。引用の際には 出版社版をご確認ご利用ください。 
2 Avian seed dispersal in a mycoheterotrophic orchid Cyrtosia septentrionalis

3

$4 \quad$ Kenji Suetsugu $^{1, *}$, Atsushi Kawakita $^{2}$, \& Makoto Kato $^{1}$

5

$6{ }^{1}$ Graduate School of Human and Environmental Studies, Kyoto University,

7 Yoshida-Nihonmatsu-cho, Sakyo, Kyoto 606-8501, Japan.

$8 \quad{ }^{2}$ Center for Ecological Research, Kyoto University, 2-509-3 Hirano, Otsu, Shiga

$9 \quad 520-2113$, Japan.

10

11 Correspondence and requests for materials should be addressed to K.S. (email:

12 kenji.suetsugu@gmail.com)

13

14

15

16

17

18

19

20

21

22 


\section{Abstract:}

3 Orchids produce remarkably small seeds lacking endosperm, which are considered to be predominantly wind-dispersed. Here, we report avian seed dispersal in a mycoheterotrophic orchid Cyrtosia septentrionalis, which occurs under closed canopies where wind is less dependable. Because some orchids occupy similar habitats and have fleshy fruits, shifts in seed dispersal strategy may be a previously unnoticed mechanism promoting the orchid's evolutionary success.

Orchidaceae is one of the most diverse groups of flowering plants on Earth. Unlike most plants, all of the $>22,000$ species of orchids are heterotrophic in their early life history stages, obtaining resources from fungi before the production of photosynthetic leaves ${ }^{1}$. Orchid seeds, therefore, contain minimal energy reserves and are numerous and dust-like, which maximises the chance of successful encounter with fungi in the substrate $^{1}$. Despite considerable interest in ways by which orchid flowers are pollinated ${ }^{2}$, little attention has been paid to how their seeds are dispersed, owing to the dogma that wind dispersal is their predominant strategy. However, here, we present evidence for seed dispersal by birds in the orchid Cyrtosia septentrionalis.

Animal seed dispersal has been implicated in a few orchid genera that produce fleshy fruits including Cyrtosia $^{3-6}$, but a compelling demonstration has hitherto been lacking. Cyrtosia septentrionalis is a non-photosynthetic, fully mycoheterotrophic orchid found in the understories of temperate forests in Japan and produces red, swollen fruits that ripen in winter. We monitored the fruits of Cyrtosia septentrionalis for a total of 2427 hours in the field using motion sensor-equipped cameras, which revealed that 
1 the their pulp was frequently eaten by four species of birds (Fig. 1 and Table 1). Of

2 these, Hypsipetes amaurotis was the most frequent pulp consumer. We directly

3 observed defecation by $H$. amaurotis in the field and confirmed through examination of

4 the faecal pellets that $H$. amaurotis ingested $C$. septentrionalis seeds and thus were not

5 consuming the pulp alone (seeds per faecal pellet, $176.1 \pm 24.2 ; N=20$ ). Of the seeds

6 sampled from $H$. amaurotis faeces, $48.8 \pm 6.5 \%(N=10)$ were viable, a figure that is

7 comparable to the seeds taken directly from intact $C$. septentrionalis fruits $(45.2 \pm 5.9 \%$,

$8 \quad N=10 ; P=0.34)$.

9 Compared to other orchids, C. septentrionalis possesses several unusual 10 characteristics that are thought to facilitate ornithochory: red, indehiscent fruit with 11 sugary pulp, a robust stem that acts as perch, and a lignified testa that protects the 12 viability of seeds inside avian digestive tracts (Fig. 1). Considering that most orchid 13 species produce pale-colored, dry capsules that dehisce when ripe to release the 14 dust-like seeds, the fruit of $C$. septentrionalis is exceptional in Orchidaceae. Red fruits 15 are usually associated with seed dispersal by diurnal birds ${ }^{7}$. The average sugar content 16 of the fruit pulp was $17.1 \pm 0.37 \%(N=20)$, which is comparable to those of other 17 bird-dispersed fruits ${ }^{8}$. In addition, the inflorescence stalk of C. septentrionalis is 18 unusually robust; of the 1219 photographs with birds feeding on C. septentrionalis fruits, 19535 had birds perching directly on the inflorescence stalk (Table 1). Thus, the robust stalk of $C$. septentrionalis may serve as a perch that facilitates fruit consumption by

21 birds, similar to the specialised perch of Babiana ringens that has been found to 22 promote bird pollination ${ }^{9}$. Finally, we found that the seeds of $C$. septentrionalis possess 23 lignified testa, which probably protects the seeds as they pass through the digestive 24 tracts of birds. 
1 Seed dispersal by wind is thought to be successful in open habitats and less 2 efficient in the understory of densely vegetated forests, where wind is less dependable ${ }^{10}$.

3 For example, in monocots, 19 of the 21 evolutionary shifts from dry fruits to fleshy

4 fruits were associated with life in shady habitats, whereas eight of the 11 reversals from

5 fleshy to dry fruits were associated with life in open sunny habitats ${ }^{10}$. Cyrtosia

6 septentrionalis is a fully mycoheterotrophic orchid that has lost its ability to

7 photosynthesise throughout its life and, instead, depends entirely on fungi for its

8 nutritive needs. Because mycoheterotrophic plants do not require light, this form of life

9 has allowed them to succeed in the dark forest understory where there are few

10 autotrophic competitors ${ }^{11}$. Thus, a shift to bird dispersal may thus have facilitated the

11 colonisation of such an environment by C. septentrionalis.

12 The gross fruit morphology and pigmentation patterns of other members of

13 Cyrtosia parallel those seen in C. septentrionalis, suggesting that avian seed dispersal is

14 widespread among the genus Cyrtosia $^{6}$. In addition, fleshy, indehiscent fruit have also

15 been documented in Rhizanthella ${ }^{4}$, a distantly related genus that has also independently

16 evolved full mycoheterotrophy. Some species of Vanilla, although not full

17 mycoheterotrophs, also have seeds with lignified testa and fleshy fruits ${ }^{5,12}$, which are

18 also considered to be dispersed by animals. Thus, shifts in seed dispersal mechanisms

19 may have played a more significant role in promoting the ecological success and

20 morphological diversity of orchids than previously thought.

\section{Methods}

\section{Field study}


1 Field studies were carried out between December 2008 and January 2009, and between

2 November 2010 and February 2011 in Gochi Town, Higashi-Ohmi City, Shiga

3 Prefecture, Japan. Consumers of C. septentrionalis fruits were observed in the field

4 throughout the duration of the field study by remote cameras, which had built-in

$5 \quad$ infrared motion sensors (Bushnell Trophy Cam Field Scan Night Vision, Bushnell

6 Corporation, USA or Sensor Camera Fieldnote, Marif Co. Ltd., Yamaguchi, Japan).

7 Each camera was set up 1 meter away from six to nine C. septentrionalis plants to

8 determine the species composition of the animals feeding on the fruits. In 2011, we

9 collected 20 fruits that had been observed being consumed by $H$. amauroti and

10 measured the sugar concentrations of fruit pulp using a refractometer (Bellingham \&

11 Stanley, Kent, UK). We deposited a voucher specimen of Cyrtosia with H. amauroti

12 feeding marks in KYO.

\section{Seed viability}

15 Orchid seeds are believed to be particularly vulnerable to stress because their testa consists of a thin layer of non-lignified cells and are unlikely to withstand the digestive

17 fluids of birds ${ }^{13}$. Therefore, we tested the viability of Cyrtosia seeds defecated by birds.

18 We observed bird visits by hiding in the vegetation and collected faecal pellets whenever we observed defecation by $H$. amauroti. We used 10 such faecal pellets for the below seed viability test. The faecal pellets were washed in distilled water, and 50

21 seeds per faecal pellet were randomly chosen for a total of 500 seeds. Viability was

22 tested using the 2,3,5-triphenyl tetrazolium chloride staining method as previously

23 described $^{14}$. In brief, seeds were pretreated in $5 \% \mathrm{Ca}(\mathrm{ClO})_{2}(\mathrm{~W} / \mathrm{V})+1 \%$ Tween-80

$24(\mathrm{~V} / \mathrm{V})$ for 6 hours. After the treatment, the seed testa was removed with tweezers, and 
1 the embryos were placed on filter paper discs immersed in a solution of $1 \%$ TTC (Tokyo

2 Chemical Industry, Japan) in $\mathrm{pH} 7$ water adjusted with $1 \mathrm{M} \mathrm{NaOH}$. The filter paper discs

3 were placed in sealed Petri dishes wrapped in aluminum foil, and incubated at $30^{\circ} \mathrm{C}$ for seven days. The viability of defecated seeds was compared with that of the same number of seeds collected directly from the fruits of 10 plants. Viability differences between seeds from fruits and faeces were compared using Student's $t$ test.

\section{Seed coat anatomy}

9 The test of seed viability revealed that seeds extracted from the faeces of $H$. amaurotis

10 remained intact. This led us to investigate the anatomy of the seed testa to explore

11 possible characteristics that allowed the seeds to withstand the digestive fluids of

12 animals. Seeds were fixed in FAA and then dehydrated in graduated $t$-butyl alcohol,

13 after which they were saturated with paraffin. Sections $(7 \mu \mathrm{m})$ were cut with a

14 microtome and attached to Haupt's adhesive-treated microscope slides. After the removal of the paraffin, slides were stained with Safranin O $(1 \% \mathrm{w}: \mathrm{v}$ in $50 \% \mathrm{v}: \mathrm{v}$

17 were stained red ${ }^{15}$.

\section{References}

24 3. Nakamura, S. I. \& Hamada, M. J. Jpn. Bot. 53, 260-263 (1978). 
1 4. Dixon, K. W., Pate, J. S. \& Kuo, J. Orchid biology, reviews and perspectives 5, 37-62

2 (1990).

3 5. Soto Arenas, M. A. \& Dressler, R. L. Lankesteriana 9, 285-354 (2010).

4 6. Yang, C. K. \& Lee, Y. I. Botanical Studies 55, 44 (2014).

5 7. Gautier-Hion, A. et al. Oecologia 65, 324-337 (1985).

6 8. Kitamura, S. et al. Oecologia 133, 559-572 (2002).

7 9. Anderson, B., Cole, W. W. \& Barrett, S. C. H. Nature 435, 41-42 (2005).

8 10. Givnish, T. J. et al. Proc. R. Soc. Lond. B 272, 1481-1490 (2005).

9 11. Bidartondo, M. I., Burghardt, B., Gebauer, G., Bruns, T. D. \& Read, D. J. Proc. $R$.

10 Soc. Lond. B 271, 1799-1806 (2004).

11 12. Cameron, K. M. in Handbook of vanilla science and technology (eds.

12 Havkin-Frenkel, D., Belanger, F.C.) 243-255. (Wiley-Blackwell, Chichester, 2011).

13 13. Garay, L. A. Proceedings of the World Orchid Conference, Singapore 1963, 170-187

14 (1964).

15 14. De Vega, C., Arista, M., Ortiz, P. L., Herrera, C. M. \& Talavera, S. Ann. Bot. 107, $16 \quad 629-637(2011)$.

17 15. Zhong, R. \& Ye, Z. H. Curr. Opin. Plant Biol. 10, 564-572 (2007).

\section{Acknowledgements}

20 We thank Drs. B. Anderson and S. Nakamura for providing comments that improved

21 this manuscript and S. Mori for field assistance. This work was partially supported by 22 the Japan Society for the Promotion of Science (No. 12J00602, K.S., and No. 22247003 , 23 M.K.). 


\section{Author contributions}

2 K.S. designed the study, conducted the experiment, and composed the manuscript. A.K.

3 and M.K. contributed to the study design and the manuscript composition.

4

5

6

7

8

9

10

11

12

13

14

15

16

17

18

19

20

21

22

23

24 


\section{$1 \quad$ Figure legend}

2

3 Figure 1 | Cyrtosia septentrionalis and its seed dispersal agents. (a-b) Reproductive

4 stem, (c) Cettia diphone perching on the stem, (d) Hypsipetes amaurotis feeding on the

5 fruit pulp, (e) fruits with feeding marks, (f) horizontal section of the fruit, (g) seeds

6 defecated from H. amaurotis, and (h) cross section of a seed. Bar $=100 \mu \mathrm{m}$. 

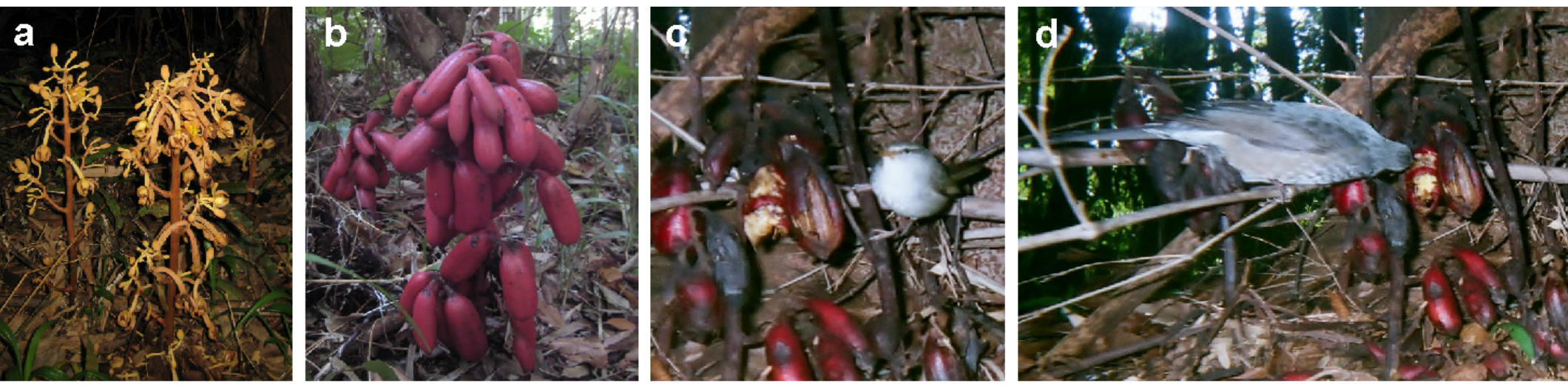

\begin{abstract}
e
\end{abstract}

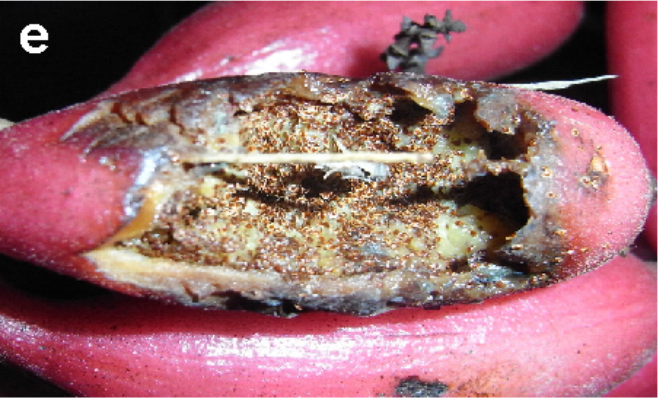

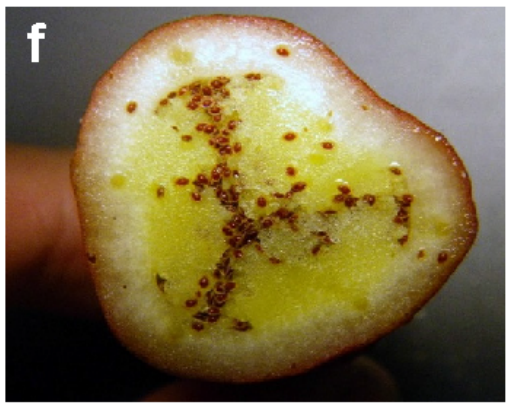

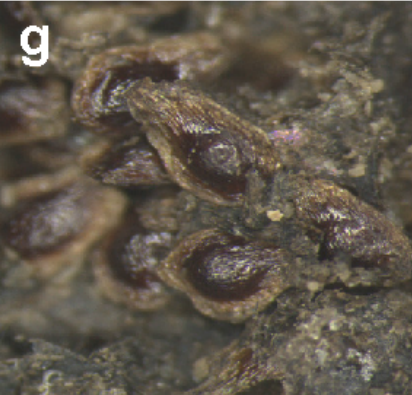

h

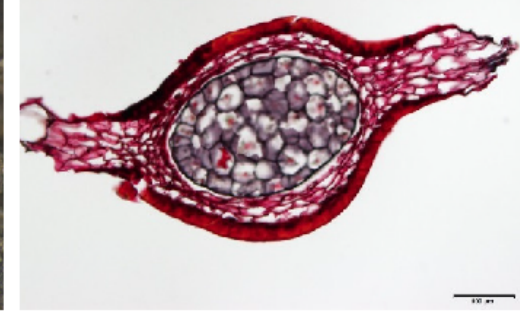


Table 1 | List of bird species captured by motion-sensor camera. Camera recordings were conducted for 219 hours between December 2008 and January 2009, and for 2208 hours between November 2010 and February 2011. Numbers given are the total numbers of (a) frames that captured each bird species, and (b) individuals that fed on the fruits. Birds were regarded as the same individual when captured in consecutive frames. Numbers in parentheses are the frames with individual birds perching on the inflorescence stalk. 2008-2009 2010-2011

(a) Frames

(b) Individuals

(a) Frames

(b) Individuals

Cettia diphone $103(10)$ 41 (6)

Hypsipetes amaurotis

$49(5)$

21 (3)

1 (1)

1 (1)

Turdus pallidus

4 (1)

4 (1)

988 (501)

$146(59)$

Garrulus glandarius

0

68 (11)

20 (7)

1 (1) 